\title{
A violência obstétrica na percepção dos profissionais que assistem ao parto
}

\section{Obstetric violence in the perception of professionals who attend}

\author{
Gessyka Mayara Soares Gomes' • Rejane Cristyane Lins de França Pereira ${ }^{2}$ \\ Flávia Emília Cavalcante Valença Fernandes ${ }^{3} \bullet$ Rosana Alves de Melo $^{4}$
}

\begin{abstract}
RESUMO
Objetivo: conhecer a percepção dos profissionais médicos e enfermeiros de um hospital público de referência materno-infantil acerca a violência obstétrica. Método: Pesquisa descritiva exploratória, e qualitativa, realizada com 22 profissionais médicos e enfermeiros, com coleta dos dados entre os meses de agosto e novembro de 2017, por entrevista semiestruturada guiada por questões norteadoras sobre o tema da violência obstétrica na rotina profissional, sendo os dados analisados pela técnica de análise de conteúdo temática. Resultados:A maioria dos entrevistados compreendem o que se configura como violência obstétrica, no entanto, muitos mostraram desconhecer as condutas a serem tomadas diante dos casos, reconhecendo-se como potenciais agressores diante das diversas situações de sobre carga e estresse do cotidiano de trabalho. As condutas como amniotomia precoce, ruptura de membrana, Kristeller, e até toques vaginais desnecessários foram referenciados pelos profissionais como condutas ainda realizadas na prática hospitalar, apesar de se mostrarem sensibilizados e enfatizarem que os treinamentos são importantes para que essa violência não se concretize. Conclusão: $O$ impacto da violência obstétrica na vida das mulheres se configura como um problema grave, devendo os profissionais de saúde atuarem no sentido de garantir um atendimento digno, respeitoso e com qualidade. Assim, ao reconhecer a existência desse grave problema que afeta mulheres nos mais distintos locais do mundo, deve-se buscar também estratégias de prevenção e enfrentamento dessa problemática, no que cocerne a própria mulher e aos profissionais de saúde que participam desse período gravídico-puerperal.
\end{abstract}

Palavras-chave: Violência Contra a Mulher. Saúde Materna. Obstetrícia. Assistência ao Parto.

\begin{abstract}
Objective: The objective was to know the perception of the medical professionals and nurses of a public hospital of maternal and child reference about obstetric violence. Method: Exploratory and qualitative descriptive research, conducted with 22 medical professionals and nurses, with data collection between August and November 2017, by semi-structured interview guided by guiding questions on the theme of obstetric violence in the professional routine, being the following: data analyzed by thematic content analysis technique. Results: Most respondents understand what is configured as obstetric violence, however, many were unaware of the conducts to be taken in front of cases, recognizing themselves as potential aggressors in the face of various situations of overload and stress of daily work. The conducts such as early amniotomy, membrane rupture, Kristeller, and even unnecessary vaginal touches were referred by professionals as conducts still performed in hospital practice, despite being sensitized and emphasizing that training is important for this violence to not materialize. Conclusion: The impact of obstetric violence on women's lives is a serious problem, and health professionals should act to ensure dignified, respectful and quality care. Thus, recognizing the existence of this serious problem that affects women in the most different places in the world, one must also seek strategies for the prevention and coping with this problem, as far as women themselves and health professionals who participate in this pregnancy-puerperal period are concerned.
\end{abstract}

Keywords: Violence Against Women. Maternal Health. Obstetrics. Childbirth Care.

I. Enfermeira. Mestre em Ciências da Saúde e Biológicas pela Universidade Federal doVale do São Francisco. Petrolina, Pernambuco, Brasil. E-mail:g_mayara@hotmail.com

2. Enfermeira do Setor de educação permanente do Hospital Dom Malan/IMIP. Mestranda em Ciências da Saúde e Biológicas da Universidade Federal doVale do São Francisco Petrolina, PE, Brasil. E-mail: rejanelinsf@gmail.com.

3. Enfermeira. Mestre em Economia da Saúde. Doutora em Inovação Terapêutica. Professora adjunta da Universidade de Pernambuco, Campus Petrolina. Colegiado de Enfermagem. Petrolina, Pernambuco, Brasil. E-mail: flavia.fernandes@upe.br.

4. Enfermeira. Mestre em Enfermagem. Doutora em Inovação Terapêutica. Professora adjunta da Universidade Federal do Vale do São Francisco. Departamento de Saúde. Colegiado de Enfermagem. Petrolina, Pernambuco, Brasil. E-mail: rosananurse@hotmail.com. 


\section{INTRODUÇÃO}

A violência é um tema que vem sendo discutido nas mais diversas proporções na sociedade e envolve aspectos socioculturais, desvelando-se no cotidiano das relações pessoais e do contexto em que estão inseridas. É um evento de pluricausalidade com conceito complexo, compreendendo origens e expressões variadas, podendo ser definida como qualquer circunstância em que um indivíduo perde o discernimento do seu papel de sujeito, sendo inferiorizado à categoria de objeto, através do uso de poder, força física ou outras formas de coibição(I).

O processo parturitivo, para muitas mulheres, vem acompanhado de inúmeras situações de abusos no âmbito das instituições de saúde. Essa realidade, que atinge diversos países do mundo, além de violar os direitos dessas mulheres a um atendimento de qualidade, coloca em risco a sua integridade física e mental em um momento de extrema singularidade. Sendo assim, além de um problema de saúde pública, tem-se uma questão de direitos humanos (2).

A violência obstétrica é um termo empregado para delinear e compreender distintas formas de violência durante a prática obstétrica profissional. Dentre elas, podem ser citados: maus tratos físico, psicológico e verbal, bem como procedimentos dispensáveis e prejudiciais, como restrição ao leito, ocitocina de rotina e impossibilitar o direito ao acompanhante ${ }^{(3)}$. Episódios de abuso, desrespeito e negligência são experienciados por muIheres durante o período gestacional, parto e pós parto, apesar de que durante $o$ parto as mulheres encontramse mais susceptíveis a tais acontecimentos ${ }^{(4)}$.

Desse modo, percebe-se que o modelo obstétrico brasileiro, marcado pela necessidade de um parto rápido, onde o respeito a autonomia da mulher em algumas situações é esquecido, favorece a ocorrência de intervenções desnecessárias, baseadas em práticas sem evidências científicas que as apoiem, condição que favorece a ocorrência de violência obstétrica ${ }^{(3)}$.

Nesse contexto, é importante refletir sobre o modelo de assistência disponibilizado a essas mulheres, considerando aspectos estruturais e a própria relação entre clientes e profissionais, contribuindo no direcionamento dos recursos disponíveis na realização da melhoria do serviço. Cabe nesse cenário, a valorização da singularidade e da legitimação de pensamentos e atitudes diante do cuidar de outra pessoa, bem como uma assistência embasada cientificamente ${ }^{(4)}$.

Assim, o Ministério da Saúde criou programas que visam melhorar a qualidade da assistência prestada à mulher no período gestacional, parto e puerpério, como exemplo a Rede Cegonha ${ }^{(5)}$. Contudo, é imprescindível que essas mulheres reconheçam seus direitos, os exijam e denunciem quando não cumpridos. É indis- pensável a formação de um profissional habilitado em prestar assistência integral de qualidade e de caráter mais humanizado(6).

Entende-se que o reconhecimento das situações de violência obstétricas perpetuadas é uma maneira de reconhecer a existência do problema e a sua forma de perpetuação no cotidiano da assistência prestada. Dessa forma, faz-se importante identificar a influência da assistência profissional voltada a mulher no seu período gravídico puerperal, sendo imperativo dar voz e promover educação permanente aos prestadores de serviços diretos desse atendimento, visto que, denota circunstâncias que por vezes, são veladas ou inexploradas. Diante do exposto, este estudo, objetivou conhecer a percepção dos profissionais médicos e enfermeiros de um hospital público de referência materno-infantil acerca a violência obstétrica.

\section{MÉTODO}

Trata-se de uma pesquisa descritiva exploratória, de abordagem qualitativa, sendo uma modalidade de pesquisa, que através de sua subjetividade, permitiu trabalhar com sentimentos, emoções e percepções dos entrevistados sobre o tema proposto ${ }^{(7)}$. A pesquisa foi realizada em um Hospital Materno-Infantil de Pernambuco, sendo esta instituição referência na área da assistência obstétrica de médio e alto risco, para os 55 municípios que compõem a rede Pernambuco/Bahia. É um hospital de nível terciário que atende exclusivamente usuários do Sistema Único de Saúde (SUS), e pertence à rede Estadual de saúde em Pernambuco e realiza aproximadamente 600 atendimentos de assistência a partos e 1.800 atendimentos mensais na emergência obstétrica.

Os participantes deste estudo foram 22 profissionais de saúde - sendo seis médicos, nove enfermeiros, três residentes de medicina e quatro residentes de enfermagem, tendo como critério de inclusão estarem atuando na assistência obstétrica há pelo menos seis meses, período estabelecido para dar fidedignidade a pesquisa; serem atuantes no período diurno e noturno; e terem assinado o Termo de Consentimento Livre e Esclarecido (TCLE). $O$ número de participantes se esgotou através da saturação teórica dos dados, em que o processo de coleta é encerrado quando as informações obtidas não trazem novos elementos que aprofundem ou subsidiem a teorização pretendida diante do objetivo estabelecido pela pesquisa ${ }^{(7)}$.

As entrevistas foram realizadas com uso de gravador portátil, em horários previamente agendados com os participantes, após rigoroso treinamento das pesquisadoras, de forma a viabilizar o correto andamento do processo e que não permitisse a perda de informações importantes para a conclusão da pesquisa. Essa etapa de coleta dos dados durou em média 25 a 30 minutos por entrevista. 
Para preservar o anonimato dos participantes, foi atribuído códigos identificadores, de acordo com a sequência em que foram entrevistados (el, e2, e3..., e22). Todos as participantes foram informadas sobre os objetivos do estudo, metodologia, riscos benefícios e aspectos éticos. As entrevistas foram iniciadas após leitura e assinatura do TCLE e foram transcritas e revisadas após escuta exaustiva das gravações.

A coleta dos dados se deu no período de agosto a novembro de 2017 , com realização de entrevista semiestruturada, composta inicialmente por dados sociodemográficos dos participantes, como profissão, idade, estado civil, religião, filhos, tempo de formação e especialização. As questões norteadoras foram: I. Compreensão sobre violência obstétrica; 2. Vivências e condutas frente aos casos de violência obstétrica; 3. Conhecimento da assistência adequada ao parto e boas práticas na assistência à gestante durante o pré-parto, parto e pós-parto; 4. Participação em capacitação ou treinamento sobre tema.

Foi utilizada a Análise de Conteúdo Temática para análise dos resultados, a qual envolve leitura compreensiva, exploração do material ou análise e síntese interpretativa, compondo assim as três etapas: pré-análise, o qual envolveu a transcrição, na íntegra, do material áudio gravado, realizado após cada entrevista; exploração do material, que compreendeu a categorização que serviu para o avanço na análise temática do material; e tratamento dos resultados com interpretações dos dados, em que realizou-se inferências e abriu-se outras pistas ou dimensões sugeridas a partir da leitura exaustiva do material, resultando nas categorias de análise ${ }^{(7)}$.

O presente estudo foi aprovado pelo Comitê de Ética em Pesquisa da Universidade Federal do Vale do São Francisco, sob o parecer de $n^{\circ} 2.108 .173$, e todos os aspectos estão de acordo com as diretrizes e normas regulamentadoras de pesquisas envolvendo seres humanos.

\section{RESULTADOS}

Os profissionais participantes do estudo eram em sua maioria do sexo feminino, com faixa etária variando entre 25 a 30 anos de idade, solteiros, sem filhos e católicos. A categoria profissional que se sobressaiu foi a enfermagem, seguida da medicina.

Apesar das diferenças existentes na formação e atuação entre essas profissões, não houve divergência marcante quanto aos discursos dos profissionais médicos, enfermeiros e/ou residentes. Ademais, quanto ao período de formação, variou de um ano e seis meses a 16 anos, e observou-se que houve melhor compreensão sobre a temática, postura frente aos casos de violência obstétrica e domínio das práticas adotadas daqueles profissionais que tinham menos tempo de formação, sendo que os mesmos referiram estar em constante atualização em obstetrícia.
Observou-se também, que apesar de o atendimento ser direcionado a mulher em seu período gravídico-puerperal, seis estavam com a especialização em andamento, dez já tinham concluído o curso, e seis profissionais não tinham pós-graduação em obstetrícia, podendo este último ser um fator limitante na compreensão das especificidades voltadas às mulheres nesse período.

Após a apresentação dos dados sociodemográficos dos participantes, e leitura exaustiva dos relatos encontrados, conseguiu-se extrair três categorias, listadas a seguir: A violência obstétrica e as situações associadas a essa problemática; A violência obstétrica na prática e a conduta profissional frente aos casos; Boas práticas e novas perspectivas na assistência a gestante durante 0 período gravídico-puerperal.

\section{A violência obstétrica e as situações associadas a essa problemática}

Quando indagados sobre o que se configura como violência obstétrica, a maioria dos profissionais pontuaram questões relevantes e fundamentais na sua identificação, percebendo essa problemática como atos de agressão verbal e física, que pode envolver até situações de menosprezo e intervenções desnecessárias.

É qualquer tipo de agressão, verbal ou fisica, que esteja ligada à puérpera, parturiente elou a gestante como um todo (el).

Toda e qualquer atitude que faça com que a mulher se sinta ofendida. [...] violentada, [...] menosprezada, que se sinta culpada por algum motivo (e3).

São intervenções desnecessárias e que passa pela autonomia da mulher (el5).

Em contrapartida, alguns entrevistados mostraram-se confusos, não sabendo de fato o que se configura como violência obstétrica dentro ou fora do seu setor de trabalho (sala de parto).

Violência obstétrica não sei se são maus tratos, se seria a palavra, mas se desfazer de algumas coisas das pacientes?! (e2).

Mas, é assim, não sei se é, se eu nomeava como violência né [...] algumas coisas que são irregulares, algumas irregularidades, ou um descaso [...], eu não sei bem se isso se enquadra como violência, entendeu? (e7).879887I-8600

Quanto aos sujeitos que podem perpetuar a violência dentro do ambiente obstétrico, os entrevistados referenciaram que as situações de violação dos direitos da muIher no período do parto é prática recorrente de vários profissionais, mesmo aqueles que não prestam assistência direta a essa mulher, iniciando desde sua chegada à instituição de saúde, podendo ser vítima de ações propagadas pelos porteiros, recepcionistas, e mesmo o pessoal responsável pela limpeza do local, como também seus próprios familiares.

O agressor pode ser pediatra, obstetra, [...] enfermeiro, técnico de enfermagem, estudantes (e2). 
[...] Os familiares, o esposo, a sogra a própria mãe e dentro do meio hospitalar (e4).

Acho que qualquer pessoa, qualquer funcionário do hospital, fisioterapia, nutrição, [...] de limpeza então. [...] Chegar na portaria e for maltratada já é uma violência obstétrica (e2I).

$O$ agressor ele pode ser desde o gestor, até o profissional que faz a ação direta (e22).

Com relação aos locais e o momento da ocorrência da violência obstétrica, foram trazidas situações em que essa ocorrência se dar desde o pré-natal; na triagem, quando a mulher chega ao serviço; no puerpério, e até mesmo no domicílio.

[...] Pode ocorrer em hospital ou no lar (el).

O tempo todo, do começo ao fim [...] desde o atendimento da triagem até na sala de parto, e até após isso mesmo, quando a paciente ainda é puérpera (e8).

[...] Desde o pré-natal até a assistência ao parto e puerpério. [...] Então pode ser numa unidade de saúde, no consultório, pode ser na maternidade, pode ser na visita domiciliar (el I).

Uma questão também observada nas ponderações trazidas, remetem uma maior ocorrência dos atos violentos durante o parto em si, não havendo sensibilidade para com um dos momentos de maior vulnerabilidade da mulher, dentro desse processo de parir.

[...], mas eu acho que o mais comum é no momento mesmo do parto [...] eu creio que não só exista na sala de parto, mas eu acho que pelo menos a maioria é lá (e7).

[...] Principalmente durante o processo de trabalho de parto e parto, [...] em que mais tem a violência obstétrica (el2).

Principalmente na sala de parto, assim, no período expulsivo da criança, né! (el9).

É de fundamental importância discutir experiências vivenciadas nas redes de trabalho sob a ótica dos profissionais, e nesse sentido, muitos relataram diversos exemplos de violência obstétrica da qual tiveram contato.

[...] Na hora de fazer não doeu, [...] dessa idade, já tem tantos filhos. Ou, mulher vai parar por aí, né? 6 filhos (e2).

[...] Pra que está chorando, se já sabia como era.Ano que vem vai estar aqui novamente pra parir (e4).

Eu ouvi do acompanhante: "Tá vendo eu disse que não era pra você fazer, agora aguente”, [...] Essa coitada já vinha recebendo uma violência da própria família (e5).

"Ah você fez agora você vai ter que parir, oooouu... pára de gritar! (el2).

Outras situações levantadas pelos entrevistados, foi a utilização recorrente de métodos durante o trabalho de parto que já foram trazidos pelas atualizações e evidências científicas como métodos não eficazes, e por vezes agressivos a saúde da mulher durante o parto.

Já vi muito fazer Kristeller durante o trabalho de parto (el0).

Fazer pressão abdominal, fazer toque é (pausa) muitas vezes, sem necessidade [...] induzir o parto por ruptura das membranas ovulares, porque tá com pressa (el8).
[...]Amniotomia é (pausa) de rotina, [...] toques vaginais desnecessários (el4).

[...] O desmembranamento manual das membranas, que a gente vê, e o uso de Kristeller, [...] e por mais que a gente chegue, tente conscientizar, ainda é rotina (el5).

Nesse contexto, o respeito que deveria existir à dignidade e à escolha da parturiente, em participar ativamente do seu cuidado, é vista por muitos profissionais como uma afronta e desrespeito a autonomia do mesmo, como pode ser evidenciado nas falas a seguir.

[...] Eu já vi agressão fisica, não luta corporal, de pegar a paciente no uso de força. Colocar naquela posição que a pessoa (profissional) achasse que fosse melhor pra ela, e não para a paciente (e6).

[...]você vê que a paciente tá no seu limite, né, e que já existe um histórico de dilatação parada, aí o médico, [...] insiste que o parto seja normal, e aí ele induz com tudo aquilo que puder imaginar e mais um pouco, inclusive com toques desnecessários [...] ignorando o cansaço, o medo da paciente e o histórico (e8).

\section{A violência obstétrica na prática e a conduta pro- fissional frente aos casos}

Uma maioria considerável dos entrevistados referiu que, apesar de considerar a violência obstétrica uma situação inadmissível de ser perpetuada contra as mulheres assistidas, se reconhecem como sujeitos propagadores de atos violentos dentro do ambiente obstétrico, mesmo sem intenção de cometê-los.

Da forma que eu vejo a violência obstétrica, ao meu ver, eu acho que todos nós somos agressores, entendeu?! (e7).

Eu acredito que eu já fui agressiva, e até foi um momento chocante pra mim eu em diversas vezes não me percebi sendo violenta, e isso foi algo que me impactou (el 7).

$\operatorname{Sim}[. .$.$] quando você vai repensar sobre aquela situação,$ [...] você percebe que o que você fez naquele determinado momento era uma violência obstétrica, aquela violência à pessoa que você tava prestando os cuidados (el2).

Por vezes, os profissionais que estão inseridos na propagação dessas situações de violência, tentam justificar os atos violentos realizados, relacionando a sua ocorrência a situações adversas às suas atribuições, situações estressantes e sobrecarga de trabalho.

[...] Devido ao estresse, à superlotação, quando tá muito cheio, às vezes você tá atendendo um paciente e o outro fica gritando por você, às vezes você acaba sendo um pouco mais grosseiro (e9).

[...]Mesmo de rotina do setor, mesmo que você se policie, você acaba cometendo (el5).

[...] A gente acaba fazendo alguns processos de seleção de prioridade né, então às vezes, por uma questão conjuntural, você tem vinte fichas na sua mesa pra atender, e você tem uma cesárea pra realizar, você acaba deixando aquela cesárea 
como prioridade e aquelas outras fichas você acaba tendo um atendimento não padronizado, não... o ideal né! (e22).

Em outras ponderações, observou-se que os profissionais entrevistados desconheciam que condutas devem ter diante de situações de violência obstétrica, mostrando nenhum empoderamento frente aos casos vistos, não percebendo a gravidade desses casos propagados, e tentando resolver as situações de forma pontual, até mesmo por medo.

Pra mim, eu acho que devo comunicar a alguém. Mas assim, o passo a passo mesmo, não sei. Ou se tem que notificar, eu não sei (el).

Fica até dificil eu chegar pra um colega e oh, não faça isso! Às vezes você chega pra um médico que já tem 30 anos de formado "não, mas eu faço isso há 30 anos e dá certo". Qual é o argumento que eu vou chegar pra ele e dizer [...] eu acho que isso partiria até de uma iniciativa do hospital [...] fazer um curso, uma orientação, uma palestra pra todos os profissionais (el3).

Assim, eu costumo ver aquilo e ignorar, porque, até pela função que a gente exerce aqui como residente, eu vou contra aquele profissional? Eu só não vou reproduzir o que ele fez e eu vou ficar na minha. Ignorar (el6).

Em contrapartida, alguns profissionais souberam expressar como conduzir os casos de violência obstétrica, para que as devidas providências frente aos atos violentos fossem tomadas.

Tem que estar treinando a equipe sempre para evitar esses determinados constrangimentos e também tem ouvidoria para notificar os profissionais (e4).

A gente descreve todo o acontecido no livro [...], a gente notifica, pra poder o hospital tomar conhecimento, e tenta consertar o erro (e7).

Orientar porque eu sei que a paciente pode tá buscando isso judicialmente também né, fazendo a denúncia (el0).

\section{Boas práticas e novas perspectivas na assistência a gestante durante o período gravídico-puerperal}

Considerando as boas práticas voltadas a mulher no ciclo gravídico-puerperal, notou-se a adoção de algumas delas no cotidiano da assistência prestada pelos profissionais, em todos os níveis de atenção ao paciente.

Partejar com atenção, ouvindo, acalmando a paciente. Orientando qual a melhor posição que pode dar um maior conforto. [...] Passar segurança pra ela, para ter um bom trabalho de parto, que se acalme (e3).

[...] Desde o desejo de escolher qual o tipo de parto a paciente quer, com quem ela vai estar... (e6).

[...] Estímulo a deambulação, os exercícios facilitadores, não deixar a paciente em dieta zero, estimular banhos, técnicas de alívio não farmacológicas pra dor (e9).

[...] Clampeamento tardio do cordão umbilical [...] outra boa prática, é a questão do RN né, do contato pele a pele com a mãe, logo de início... já iniciar o aleitamento (el4).

[...] orientar a mulher quanto a questão com a o aleitamento materno, os cuidados dessa mãe com $R N$ em casa, com o coto umbilical (e20).

Sabe-se que, para as mudanças de hábitos acontecerem, faz-se necessária a abordagem de todos os atores envolvidos nesse processo, no sentido de buscar o conhecimento e adequado seguimento, afim de evitar a banalização do cuidado, bem como manutenção adequada dos cuidados já bem estabelecidos. Dessa forma, os entrevistados mostraram-se convencidos que a informação é a base para a mudança de comportamento.

Eu acho que é orientação. Porque ela pode até não reconhecer, que pode estar sendo violentada e não saber, não achar que aquilo é uma violência pra ela [...] orientar a gestante e o profissional né (e6).

[...] Eu sempre tento orientar ela, conversar pra ela entender o que tá acontecendo com ela, [...] porque tem paciente que trava, perde a confiança de que ela é capaz (e9).

[...] Discutindo novo protocolo de assistência pré-natal, [...] a inclusão do plano de parto [...] os cursos de formação de gestantes de pré-natal, preparação pra parto e puerpério e gravidez em si (e22).

\section{DISCUSSÃO}

A enfermagem é uma das categorias profissionais mais numerosas na área da saúde, com uma predominância de profissionais do sexo feminino, em contraponto a medicina, que tem uma maioria de integrantes do sexo masculino. Essas particularidades já são evidenciadas pela literatura, que reafirma a predominância do gênero feminino na enfermagem, entretanto já identifica-se uma tendência a feminização da medicina no país ${ }^{(8)}$.

Os participantes do estudo, apesar de estarem em uma faixa etária considerada adulto e adulto jovem, mostraram experiência e um bom conhecimento sobre a problemática da violência obstétrica, não obstante possibilitando a identificação de suas particularidades. Outro fator relevante, é que, apesar de a literatura trazer que profissionais solteiros e sem filhos tem menor sensibilidade, nesta pesquisa, observou-se um contraponto, em que os profissionais mostraram maior sensibilidade aos casos de violência obstétrica, compreendendo em sua maior parte, através das falas, o momento gestacional/puerperal vivenciado pelas mulheres ${ }^{(9)}$.

Nesse sentido, estudo realizado com enfermeiras obstétricas, evidenciou-se que o profissional desenvolve sua própria concepção de violência fundamentado do seu discernimento sobre as particularidades que transcendem as relações humanas e familiares, bem como a estima e as crenças acerca do próprio meio pessoal, que podem influenciar sobre o desenvolvimento das atividades profissionais realizadas na assistência a mulher ${ }^{(10)}$. 
Quanto ao fato de a maioria referir ter uma religião definida, foi visto como uma informação relevante e com potencial de influenciar sobre os parâmetros que condicionam o desenvolvimento das atividades durante o turno de trabalho, podendo ter relação positiva diante das adversidades e situações vivenciadas ${ }^{(11,12)}$.

Considerando os achados sobre o que se configura como violência obstétrica, reitera-se que esta pode ser denominada como situações que envolvem atos de agressão verbal, física, psicológica, bem como estrutural/institucional, ou mesmo por negligência assistencial, através de processos e uso inadequado de tecnologias na assistência, voltados a mulheres no pré-parto, parto e puerpério imediato ${ }^{(13)}$, tendo sido estes aspectos contemplados na fala de muitos entrevistados.

A violência obstétrica envolve, além dos aspectos levantados, uma assistência negligenciada, preconceito de cunho social, bem como, o uso inapropriado de tecnologias e procedimentos durante o ciclo gravídico -puerperal sem o consentimento explícito e informado da gestante/parturiente ${ }^{(14)}$. Essas ações podem ser praticadas por familiares, estranhos, profissionais e instituições, dentro e fora do ambiente hospitalar ${ }^{(3,14)}$. No entanto, apesar de ter um conceito bem abrangente, houveram profissionais que não conseguiram relatar os aspectos que envolvem essa problemática, nem mesmo suas características mais recorrentes.

Ademais, essa violência propagada contra a mulher, mesmo em período de vulnerabilidade, está relacionada às questões de gênero e das fragilidades apresentadas durante esse período gravídico-puerperal, que coloca a paciente em situação de desvantagem por não conseguir exigir a garantia de seus direitos e nem tampouco sair dessas situações de violência propagada. Isso é reafirmado outro estudo(14), que mostra haver uma disparidade das relações de poder que se construiu entre a interação profissional de saúde-paciente, que é transformada em desigualdade de gênero, cujo evento está intimamente relacionado ao fato de serem mulheres, ainda, pacientes, nulificando seus direitos.

Reitera-se que a prestação de assistência direta à mulher durante no seu ciclo gravídico-puerperal pode ser ofertada por diversos profissionais, como médicos, enfermeiros, técnicos em enfermagem, pediatras, neonatologistas, anestesiologistas, residentes de enfermagem obstétrica e neonatal, graduandos de obstetrícia e médicos residentes ${ }^{(15-17)}$. E de forma indireta, há os cuidados dos fisioterapeutas, psicólogos, estudantes de graduação, doulas, educadores perinatais, entre outros ${ }^{(16)}$, sendo que a propagação da violência obstétrica ocorre desde o domicílio da mulher, até a entrada nos serviços de saúde, propagada por qualquer um desses agentes citados.

A ocorrência de agressão verbal, perpetuada muitas vezes por gritos e comentários desnecessários, que vão desde questionamentos mais sutis à julgamentos sobre a vida pessoal da mulher, trazidos nas falas de muitos entrevistados, corrobora com os achados de estudos realizados com gestantes/parturientes/puérperas em outros centros obstétricos, mostrando total desrespeito no momento de parição dessas mulheres ${ }^{(13,18)}$.

Muitos profissionais refeririam haver a exacerbação da violência no momento do parto, também com a realização de manobras e métodos de trabalho já desaprovados pela literatura científica, como a manobra de Kristeller, episiotomia sem indicação e amniotomia precoce. As Diretrizes Nacionais da Assistência ao Parto Normal ${ }^{(17)}$ orientam que a manobra de Kristeller não deve ser realizada no segundo período do trabalho de parto.

Entretanto, assim como neste estudo, pesquisa realizada com profissionais de saúde de centro obstétrico, mostrou que, apesar de reconhecerem que tal manobra é proscrita, continuam a realizá-la, não registrando sua prática em prontuário. Reitera-se que, a plenária do Conselho Federal de Enfermagem proíbe a participação de profissionais de Enfermagem nessa manobra ${ }^{(19)}$.

Já considerando a amniotomia precoce, associada ou não à ocitocina, as evidências científicas esclarecem que não deve ser realizada de rotina em mulheres em trabaIho de parto que estejam progredindo bem, e que, apesar de a episiotomia ter se apresentado como método cirúrgico mais comum do mundo, sua introdução nas práticas não apresenta clareza sobre sua efetividade. E nesse sentido, as recomendações enfatizam a modificação dessa prática para algo mais restrito e não mais rotineiro( ${ }^{(13,20)}$.

A Portaria que regulamenta o Programa de Humanização do Parto e Nascimento, ressalta como dever das maternidades, receber a mulher, seu bebê e familiares com dignidade, o que demanda caráter ético pelos profissionais, ofertando um espaço acolhedor e a adoção de medidas que favoreçam o bem-estar da paciente em todo o processo do parto e do nascimento, evitando práticas intervencionistas desnecessárias, que apesar de ainda serem tradicionalmente realizadas, não são recomendadas e podem conduzir danos e riscos para o binômio mãe-bebê $\hat{e}^{(13)}$.

Considerando as falas dos participantes que tentam justificar a propagação de atos de violência velados, voltados às mulheres em trabalho de parto, que também foi defendido por outro autor ${ }^{(4)}$, ressalta-se que as maternidades no Brasil estão superlotadas e com infraestrutura bastante precárias, além do déficit de profissionais obstetras e a baixa remuneração no setor público. Entretanto, não se pode permitir que todas essas particularidades, associadas ao excesso de tecnicismo, deixem de lado um atendimento humanizado, com respeito aos indivíduos, uma vez que a valorização da vida humana deve ser 
mantida sobre quaisquer dificuldades enfrentadas pelos profissionais, no momento da prestação da assistência ${ }^{(20)}$.

Vale ressaltar que, apesar de muitos profissionais referirem não saber quais medidas tomarem diante da percepção de que a mulher está em situação de violência obstétrica, trata-se de um agravo de notificação compulsória, por parte dos profissionais de saúde, assim como qualquer outro tipo de violência sofrida pelos indivíduos. Essa obrigatoriedade é determinada em Lei, onde está estabelecida a notificação compulsória em território nacional nos casos de violência contra a mulher, que forem atendidas em serviços de saúde, públicos ou privados, devendo o profissional de saúde conhecer e aplicar essa medida. Além disso, a mulher violentada pode procurar vários outros órgãos para apurar os fatos e tomar as devidas providências ${ }^{(13)}$.

Outro ponto importante levantado pelos entrevistados, refere-se às boas práticas que eles referiram realizar, envolvendo todo ciclo gravídico-puerperal, assim como as ações voltadas ao bem estar do recém-nascido. Através das diretrizes publicadas pelo Ministério da Saúde ${ }^{(17)}$, elaborado através de evidências científicas, as ações voltadas para o cuidado da mulher em seu ciclo gravídico -puerperal, apresentou uma nova roupagem.

As diretrizes supracitadas, estabelecem que a gestante tem direito de acesso a métodos de alívio da dor, incluindo os não farmacológicos (banheira, chuveiro, massagens, entre outros), analgesia regional e outras substâncias analgésicas, e a mulher deve ser incentivada a adotar qualquer outra posição que ela achar mais confortável. Ressalta-se também, os cuidados com o recém-nascido, sendo recomendado estimular as mulheres a terem contato pele-a-pele imediato com a criança logo após o nascimento, como também, na conduta fisiológica no terceiro período, clampear o cordão apenas após a parada da pulsação ${ }^{(17)}$.

Como foi trazido por alguns participantes da pesquisa, com relação ao direito ao acompanhante, vale ressaltar que desde o ano de 2005, está estabelecido que os serviços do Sistema Único de Saúde, da rede própria ou conveniada, são obrigados a permitir a presença de um acompanhante da gestante, de sua escolha, durante o trabalho de parto, parto e puerpério imediato, assegurando que a humanização da assistência à mulher e ao neonato durante o ciclo gravídico-puerperal esteja presente em todo esse processo ${ }^{(13)}$.

\section{CONSIDERAÇÕES FINAIS}

O estudo mostrou que a maioria dos profissionais entrevistados compreendem o que se configura como violência obstétrica, bem como suas formas de propagação, e veem diversos outros profissionais como propagadores dessa violência, desde a entrada da gestante no serviço. No entanto, muitos mostraram desconhecer as condutas a serem tomadas diante dos casos de violência obstétrica, e se reconhecem como potenciais agressores, diante das diversas situações de sobre carga e estresse do cotidiano de trabalho.

As condutas como amniotomia precoce, ruptura de membrana, Kristeller, e até toques vaginais desnecessários foram referenciados pelos profissionais como condutas ainda realizadas na prática hospitalar. No entanto, muitos já se sentem sensibilizados e enfatizam que a orientação e treinamentos são importantes para que essa violência não se concretize.

Ressalta-se que, o impacto da violência obstétrica na vida das mulheres deve ser considerado grave, devendo ser passível de penalidades aqueles que praticam essa violência. Criminalizá-la, a exemplo de outras formas de violência contra a mulher, pode ser uma alternativa na busca por soluções para esse problema. Ademais, os profissionais de saúde devem atuar no sentido de garantir um atendimento digno, com qualidade e tratamento respeitoso, considerando os direitos conquistados pelas mulheres no campo obstétrico.

Ao reconhecer a existência desse grave problema que afeta mulheres nos mais distintos locais do mundo, deve-se buscar também estratégias de enfrentamento. Ressalta-se que a proposição de estratégias de prevenção e enfrentamento do evento perpassa pela formação acadêmica, pela conscientização das mulheres, pela mobilização social, pela criação de leis e políticas públicas, em um desafio conjunto para garantir-lhes uma assistência obstétrica livre de violência e firmada nos direitos sexuais e reprodutivos.

Como limitações do estudo, pode-se pontuar a baixa adesão de alguns profissionais médicos em participar da pesquisa, por falta de disponibilidade de tempo e resistência em contribuir com a coleta de dados do estudo. 


\section{REFERÊNCIAS}

I. Sauaia ASS, Serra MCM. Uma Dor Além do Parto:Violência Obstétrica em Foco. Rev Direit Hum Efetivid. 2016 [cited 2018 Jan 05]; 2(I): I28-I47. Available from: file:///C:/Users/ Dell/Downloads/I076-2I52-2-PB.pdf

2. World Health Organization. The prevention and elimination of disrespect and abuse during facility-based childbirth. Geneva:WHO; 2015 [cited 2016 Feb 02]. Avalilable from: http://apps.who.int/iris/bitstream/I0665/I34588/I/WHO_ RHR_14.23_eng.pdf?ua= I \&u a=I

3. Diniz SG, Salgado HO, Andrezzo HFA, Carvalho PGC, Carvalho PCA, Aguiar CA, et al. Abuse and disrespect in childbirth care as a public health issue in Brazil: origins, definitions, impacts on maternal health, and proposals for its prevention. Journal of Human Growth and Development. 2015 [cited 2018 Jan 07]; 25(3): 377-384. Available from: file://C:/Users/Dell/Downloads/ 106080-193 |43- I-PB.pdf

4. Pereira JS, Silva JCO, Borges NA, Ribeiro MMG, Auarek LJ, Souza JHK. Violência obstétrica: ofensa à dignidade humana. Brazilian Journal of Surgery and Clinical Research. 2016 [cited 2018 jan 08]; I5(I):I03-108. Available from: http:// www.repositorio.ufop.br/bitstream/ / 23456789/6646/l/ ARTIGO_Viol\%C3\%AAnciaObst\%C3\%A9tricaOfensa.pdf

5. Brasil. Ministério da Saúde. Portaria $n^{\circ} 1.459$, de 24 de junho de 201 I [cited 2018 jan 08]. Available from: http://bvsms.saude.gov.br/bvs/saudelegis/gm/20I I/prt I459_24_06_201 I.html

6. Coelho KR.Avaliação do grau de implantação do programa de humanização do parto e Nascimento no Médio Vale do Jequitinhonha em Minas Gerais [tese]. Doutorado em Enfermagem - Escola de Enfermagem, Universidade Federal de Minas Gerais. Belo Horizonte. 2014. [cited 2018 fev 20] Available from: http://www.bibliotecadigital.ufmg.br/dspace/bitstream/handle/I843/ANDO-9SRKJ9/kellen_rosa_coelho.pdf?sequence= I

7. Minayo MCS. $\bigcirc$ desafio do conhecimento. Pesquisa qualitativa em saúde. I $3^{\mathrm{a}}$ ed. São Paulo: Hucitec; Rio de Janeiro. 2013.

8. Scheffer M, Cassenote A, Biancarelli A. Demografia Médica no Brasil 2018. Faculdade de Medicina da USP. Conselho Regional de Medicina do Estado de São Paulo. Conselho Federal de Medicina. São Paulo, SP. Cremesp, 2018. [cited 2018 abril 15]; Available from: http://www.epsjv.fiocruz.br/ sites/default/files/files/DemografiaMedica2018\%20(3).pdf

9. Jardim DMB, Modena CM. A violência obstétrica no cotidiano assistencial e suas características. Rev. Latino-Am. Enfermagem. 2018. [cited 2019 dezembro 25]; Avalilable from: http://www.scielo.br/pdf/rlae/v26/pt_0104-I I69-rlae-26-e3069.pdf

10.Aguiar JM, D'Oliveira AFL, Schraibe LB.Violência institucional, autoridade médica e poder nas maternidades sob a ótica dos profissionais de saúde. Cad saúde pública [Internet]. 2013 [cited 2017 Jan 28]; 29(I I): 2287-96. Available from: http://www.scielo.br/pdf/csp/v29n I I/I5.pdf

II. Neto EFS. Religião, religiosidade e espiritualidade: uma compreensão a partir da Ciência da Religião. Sacrilegens. 2018 [cited 2019 Dez 25]; 02(I5): I477-508.Available from: http://www.ufjf.br/sacrilegens/files/2019/04/28.pdf.

12. Faria JB, Seidl EMF. Religiosidade e enfrentamento no contexto de saúde e doença: revisão de literatura. Psicologia: reflexão e crítica. 2005 [cited 2019 Dez 27]; 18(3): 38I89. Available from: http://www.scielo.br/pdf/prc/v18n3/ a $12 v \mid 8 n 3 . p d f$.

13. Brasil, Humanização do parto. Nasce o respeito: informações práticas sobres seus direitos / Organização,Assessoria Ministerial de Comunicação; Coordenação, Maísa Silva de Melo de Oliveira; Redação,Andréa Corradini Rego Costa e Maísa Melo de Oliveira; Revisão Técnica, Comitê Estadual de Estudos de Mortalidade Materna de Pernambuco. -- Recife: Procuradoria Geral de Justiça, 2015. [cited 2017 Nov I0]; Available from: http://www.mppe.mp.br/mppe/attachments/article/4240/cartilha\%20humanizacao\%20do\%20 parto\%20pdf.pdf

14. Oliveira VJ, Penna CMM. Discussing obstetric violence through the voices of women and health professionals. Texto contexto - enferm. [Internet]. 2017 [cited 2018 09]; 26(2): e065000 I5.Available from:http://www.scielo.br/scielo.php?script=sci_arttext\&pid=SO I 04-070720 I 700020033 I \&lng=en.

15. Gomes AM. Da Violência institucional à rede materna e infantil: Desafios e possibilidades para efetivação dos direitos humanos e redução da mortalidade. In Cadernos Humaniza SUS:Volume 4 - Humanização do parto e nascimento. Brasília, DF: UECE/Ministério da Saúde, 2014 [cited 2018 fev 04].Available from: http://www.redehumanizasus.net/sites/default/files/ caderno_humanizasus_v4_humanizacao_parto.pdf.

16. Ministério da Saúde (BR). Secretaria de Atenção à Saúde. Departamento de Ações Programáticas Estratégicas. Gestação de alto risco: manual técnico / Ministério da Saúde, Secretaria de Atenção à Saúde, Departamento de Ações Programáticas Estratégicas. - 5. ed. - Brasília: Editora do Ministério da Saúde, 2012 [cited 2018 mar 0I].Available from: http://bvsms.saude.gov.br/bvs/publicacoes/manual_tecnico_gestacao_alto_risco.pdf

17. Ministério da Saúde (BR). Secretaria de Ciência, Tecnologia e Insumos Estratégicos. Departamento de Gestão e Incorporação de Tecnologias em Saúde. Diretrizes nacionais de assistência ao parto normal: versão resumida [recurso eletrônico] / Ministério da Saúde, Secretaria de Ciência, Tecnologia e Insumos Estratégicos, Departamento de Gestão e Incorporação de Tecnologias em Saúde. - Brasília: Ministério da Saúde. 2017 [cited 2018 abril 05]. Available from: http://bvsms.saude.gov.br/bvs/publicacoes/diretrizes_nacionais_assistencia_parto_normal.pdf

18. Silva MG. Violência Obstétrica na visão de enfermeiras obstétricas. São Paulo: Rev Rene. 2014 [cited 2018 fev 04]; I5(4): 720-8. Available from: http://repositorio.ufc.br/ri/ bitstream/riufc/ I 1479/1/20 I4_art_mgsilva.pdf

19. Brasil. Conselho Regional de Enfermagem. Autarquia Fede- 
ral criada pela Lei $N^{\circ} 5.905 / 73$. Parecer técnico COREN/ SC $N^{\circ} 001 / C T / 2016$ [cited 2018 fev 12]. Available from: http://www.corensc.gov.br/wp-content/uploads/2016/06/ Parecer-T\%C3\%A9cnico-00I-2016-CT-Sa\%C3\%BAde-MuIher-Manobra-de-Kristeller.pdf

20. Bohren MA, Hunter EC, Munthe KHM, Souza JP, Vogel
JP, Gulmezoglu AM. Facilitators and barriers to facility- based delivery in low- and middle-income countries: a qualitative evidence synthesis. Reprod health. 2014 [cited $2018 \mathrm{fev}$ 12]; II(I): 3-I7. Available from: https:// reproductive-health-journal.biomedcentral.com/articles/I0.I I86/I742-4755-I I-7| 